\title{
Valores e desigualdade de gênero Mediações entre participação política e representação democrática
}

\author{
Values and gender inequality \\ Mediations between political participation and \\ democratic representation
}

Clara Araújo*

\begin{abstract}
Resumo: $O$ artigo tem por objetivo refletir acerca da relação entre valores sobre política, desigualdades de gênero em espaços sociais e presença de mulheres na representação política. Foca na cultura política, nos valores e nas implicações para o envolvimento político. A primeira parte apresenta as premissas conceituais e teóricas que embasam a investigação. A segunda apresenta dados de surveys e informações empíricas para discutir essas mediações. $\mathrm{O}$ intuito é analisar essa relação no sentido valores-participação-representação. Explora-se o argumento de que valores de descrença e desconfiança na política têm impactos sobre a propensão à participação das mulheres em espaços associativos e na política em si e, consequentemente, sobre o gap de gênero na representação. Os resultados sugerem tendências contraditórias no Brasil. Valores abstratos sobre democracia se ampliam, inclusive entre as mulheres, mas a confiança nas instituições e dados sobre participação sugerem possíveis impactos sobre a participação e o ingresso na Representação.
\end{abstract}

Palavras-chave: Desigualdades de gênero e política. Feminismo e política. Valores de gênero e política. Desigualdade de gênero e participação política.

Abstract: The article aims to reflect on the relationship between values on politics, gender inequalities in social spaces and presence of women in political representation. It focuses on the political culture, the values and implications for political involvement. The first part presents the conceptual and theoretical assumptions underlying research. The second presents survey data and empirical information in order to discuss these mediations. The paper analyzes this relationship in the following vector: valuesparticipation-representation. It explores the argument that distrust and disbelief in politics have an impact on the propensity to women's participation in associative spaces and politics itself. Consequently, on the gender gap in representation. The results

\footnotetext{
* Doutora em Sociologia pela Universidade Federal do Rio de Janeiro (UFRJ, Rio de Janeiro, RJ, Brasil), professora e pesquisadora do PPG em Ciências Sociais da Universidade do Estado do Rio de Janeiro (Uerj) no Rio de Janeiro, RJ, Brasil, bolsista produtividade do CNPq e vicecoordenadora do Núcleo de Estudos sobre Desigualdades Contemporâneas e Relações de Gênero (Nuderg)<claramaria.araujo@gmail.com>.
} 
suggest contradictory trends in Brazil. Abstract values of democracy are extended, also among women, but confidence in the institutions and data on participation suggest possible impacts on propensity to associative participation and entry into the political representation.

Keywords: Gender inequalities and politics. Feminism and politics. Gender and political values. Gender inequality and political participation.

\section{Introdução}

O objetivo deste artigo é analisar a relação entre a presença de mulheres em instâncias de representação política e duas dimensões consideradas relevantes para compreender essa representação: os valores e as atitudes em relação aos aspectos políticos, institucionais e de gênero em contextos mais amplos, apoiado aqui no conceito de cultura política; e as opiniões e práticas em relação à participação, como tema que remete ao interesse, ao envolvimento ou à inserção em ações de políticas públicas, de interesses comunitários ou da política institucional. O trabalho tenta compreender essa inter-relação a partir da apresentação de dados empíricos e de análises qualitativas, sem o intuito de medir ou testar relações causais e diretas.

$\mathrm{O}$ artigo explora possíveis fatores que operem como filtros preliminares em relação à participação política. A análise toma como problema a presença de mulheres no legislativo, espaço político por excelência, que se tornou paradigmático da presença das mulheres na política institucional e indicador de igualdade democrática. O intuito é refletir sobre as conexões entre política e valores. Apresenta informações selecionadas em pesquisas empíricas baseadas em surveys, cujos objetivos envolvem: investigar valores e crenças em relação às instituições políticas e a outros tipos mais comuns de instituições; em relação à democracia como regime político; e em relação ao envolvimento e crença na participação social e política. São apresentados também outros resultados parciais de pesquisas com metodologias semelhantes, mas focadas no tema deste texto: a relação entre gênero e participação. Os dados fazem parte de pesquisa mais ampla, cujo objetivo é compreender o caso brasileiro - baixos índices de participação política das mulheres nas instâncias de representação -, com base na comparação com outros países da América Latina. ${ }^{1}$

\footnotetext{
${ }^{1}$ Pesquisa apoiada pelo CNPq e intitulada "Relações entre percepções dos brasileiros sobre política, gênero e a presença das mulheres nas instâncias de representação política". Um dos eixos é a comparação das informações do Brasil com as de outros países da América Latina, com base em surveys que investigam questões relacionadas com o tema de pesquisa. As fontes são o Consórcio Latinobarômetro e o World Value Survey, além de um terceiro survey, o América Barômetro.
} 
Neste trabalho, as informações e o foco se referem ao caso brasileiro, embora parte da análise remeta à perspectiva comparada que orienta a investigação mencionada. A comparação temporal está centrada, sobretudo, em dois momentos: o Latinobarômetro abarca os anos de 1995 e de 2015. Outros dados auxiliares se referem ao ano de 2014 (World Values Survey, 2014). ${ }^{2}$

A partir dos anos de 1990 muitos países adotaram uma política afirmativa na esfera institucional visando a alterações na presença feminina nos espaços decisórios: as políticas de cotas para cargos eletivos de poder em governos, notadamente para cargos legislativos. Duas décadas depois essa política foi consolidada como "caminho curto" 3 para o acesso das mulheres aos espaços decisórios. ${ }^{4}$ A maior parte dos estudos identifica na aplicação das cotas a variável explicativa da mudança na composição numérica das mulheres nos parlamentos latino-americanos. Com base em vários tipos de investigação, as dimensões institucionais do sistema político e eleitoral foram consideradas relevantes para explicar o fenômeno do crescimento da presença de mulheres na política na região. Trata-se de variável significativa mesmo quando analisada em conjunto com outras variáveis do sistema político e algumas não diretamente relacionadas com a política, como a inclusão de IDHs, de índices de gênero da ONU e de outros indicadores (Araújo e Alves, 2007; Archenti e Tula, 2008; Krook e Mackay, 2011; Krook e Norris, 2014; Piatti-Crocker, 2011; Schwindter-Bayer, 2010).

Ainda que evidências apontem para a relevância de fatores institucionais, em geral não se desconhece o papel de outros condicionantes socioculturais e econômicos (ademais dos históricos, assumidos como pressuposto explicativo da exclusão das mulheres das democracias representativas em seu nascedouro). Nesse sentido, tais fatores ou dimensões são considerados tanto intervenientes como resultantes, e, para alguns autores, imprescindíveis para compreender como outras dimensões e fatores podem, também, responder pelas condições de participação e de ingresso na política (Almeida et al., 2012; Santo, 2010; Norris, 1993; 2007; Dulmer et al., 2015; Miguel et al., 2015). Propensões a valores menos tradicionais, inclusive em relação às eleições, assim como o interesse por política, necessitariam, então, ser discutidos à luz dos indicadores de desigualdades socioeconômicas, demográficos e da socialização (Krook e Norris, 2014).

\footnotetext{
${ }^{2}$ Um leque de perguntas de interesse da pesquisa se repetem em ambos os momentos; 1995 é marco no debate sobre gênero e poder na América Latina, a partir da Conferência de Beijing; é o ano anterior à adoção das cotas eleitorais no Brasil. Algumas das perguntas selecionadas eventualmente não estiveram presentes no ano de 2015, mas em anos próximos. Nas tabelas e gráficos, quando isto ocorre, é assinalado com o símbolo *.

3 Termo cunhado por Dalherup (2006) e que se tornou uma expressão para falar de cotas.

${ }^{4}$ Ver site da Inter-parliamentary Union, IPU <www.ipu.org> (17 jun. 2016).
} 
Em se tratando das relações de gênero, agrega-se a isso, condicionantes e obstáculos efetivos, decorrentes e associados às percepções e às atribuições dos lugares percebidos como naturais e apropriados para homens e mulheres. A percepção corrente de espaços sociais não apenas separados, mas quase dicotômicos, como nos casos de espaço doméstico e espaços públicos, responde por parte importante desses condicionantes. A hipótese orientadora é a de que a estagnação brasileira da presença de mulheres nos espaços de representação se explica a partir de múltiplos aspectos, embora haja comprovada relação causal entre cotas, tipo de lista eleitoral e aumento da eleição de mulheres. Por isso, necessita ser pensada em comparação com outros países, mas também e internamente, em relação às dimensões intrassistêmicas e fora do âmbito do sistema institucional. Contextos locais e condicionantes culturais de valores vinculados à ideia de direitos, cidadania e à cultura política responderiam também pelas lógicas partidárias que, por sua vez, respondem pelo resultado final dos recrutamentos políticos eleitorais.

$\mathrm{O}$ artigo está estruturado da seguinte maneira. Primeiro apresenta de forma resumida as problemáticas conceituais que serviram de base para a pesquisa e discute brevemente conceitos-chave para pensar essa articulação entre representação, participação e valores: cultura política e participação. Em seguida apresenta alguns dados gerais sobre a presença política atual de mulheres nos espaços eletivos e indica, esquematicamente, as premissas e dimensões implicadas nos estudos que tentam compreender o processo no âmbito das instituições políticas. No terceiro momento introduz parte dos dados selecionados, sobretudo, na pesquisa do Latinobarômetro, reforçados, também, por discussão sobre análise desenvolvida com base em outros surveys que tomam os mesmos países como unidades de análise. Esses consórcios incluem perguntas atitudinais, associativas e individuais, consideradas pertinentes e relacionadas ao tema mais amplo "democracia e valores". Busca, a seguir, explorar como as condições diretamente associadas aos valores de gênero e relacionadas com o tempo e a divisão sexual do trabalho operam nessas mediações. Por fim, tece algumas considerações, a título de conclusão.

\section{A presença das mulheres em números e em sua dimensão analítica}

Entre as diversas manifestações da desigualdade de gênero no Brasil, a desigualdade nas esferas de poder, mais especificamente, no acesso ao poder político institucional, tem se apresentado como uma das mais amplas e recorrentes. Entre países da América Latina o Brasil possui um dos maiores diferenciais em presença de mulheres nos espaços de representação. Como 
mostram vários estudos, esse quadro pouco tem sido alterado nas duas últimas décadas, contrastando, inclusive com a maior parte dos países da região (Schwindter-Bayer, 2010; Piatti-Crocker, 2011). A tabela 1 apresenta os dados gerais dessa presença e de sua estagnação nos espaços institucionais que envolvem a representação. ${ }^{5}$ Como esse quadro e esse processo têm sido analisados pela literatura e por atores do campo político na região e no país, será sumarizado de forma esquemática a seguir.

Tabela 1. Percentual de mulheres eleitas para cargos nos executivos e nos legislativos no Brasil nas eleições de 2012 e de 2014

\begin{tabular}{lc}
\hline \multicolumn{1}{c}{ Cargo } & $\begin{array}{c}\text { \% de eleitas sobre } \\
\text { total de eleitos }\end{array}$ \\
\hline Governo estadual & 3,7 \\
Senado & 18,5 \\
Câmara Federal & 9,9 \\
Assembleias legislativas estaduais e distrital & 11,3 \\
Prefeituras & 12,3 \\
Câmaras de vereadores & 13,3 \\
\hline
\end{tabular}

Fonte: TSE, 2015. Elaboração própria.

A maior parte dos estudos que examinaram as variações da presença política de mulheres na América Latina, identifica nas "cotas por sexo para candidaturas eleitorais", fator determinante para explicar o crescimento dessa presença nos parlamentos. Concluiu-se que a eficácia de aplicação dessas cotas para aumentar a eleição de mulheres depende, em primeiro lugar, do sistema eleitoral e, dentro deste, do tipo de lista partidária de votação de candidatos - quando aplicadas, as cotas são bem mais eficazes nos sistemas de listas fechadas, e bem menos ou nada eficazes nos sistemas de listas abertas. Mesmo no sistema de lista fechada, para se tornarem eficazes essas políticas de cotas necessitaram e necessitam de três requisitos: legislações mais duras e mais claras quanto a obrigações dos partidos políticos em cumprirem os percentuais mínimos; definição de alternâncias na ordem de apresentação dos nomes nos sistemas de lista fechada, de modo que os nomes das mulheres não fiquem na base das listas, ou seja, não fiquem entre aqueles de quem não se espera sucesso eleitoral; e legislações mais punitivas nos casos de não cumprimento de alguns dos requisitos anteriores. Conforme várias das

\footnotetext{
${ }^{5}$ Dados do TSE mostram essa estagnação.
} 
pesquisas mencionadas, o requisito apresentado no item anterior, puramente institucional e procedimental, resultou da interveniência de dois tipos de atores políticos: os movimentos de mulheres, com seu envolvimento e sua mobilização - movimentos internos aos partidos, através de suas dirigentes, parlamentares elou de departamentos ou núcleos, e também de movimentos sociais de mulheres -, importantes para exigir leis mais eficazes, para pressionar os partidos e para tornar a demanda conhecida e apoiada pelos diversos setores da sociedade; e o ator institucional "tribunais eleitorais" - no Brasil leia-se Tribunal Superior Eleitoral, com suas disposições para fiscalizar, fazer cumprir a lei e punir partidos que a descumprissem. Com efeito, sugeriu a associação entre ação política, disposição procedimental em determinada direção e participação sociopolítica. Mas esse mapeamento indicou, também, que padrões de resultados encontrados de acordo com sistemas de listas eleitorais, apresentam variações contextuais. Entre tais fatores estariam os contextos políticos específicos em um dado momento e em um dado processo; condições socioeconômicas e demográficas; e ainda a cultura política e a relação com valores de gênero e com as condições materiais de igualdade ou desigualdade entre homens e mulheres (Dahlerhup, 2006; Araújo e García Quesada, 2006; Archenti e Tula, 2008; Franceschet et al., 2012; Piatti-Crocker, 2011).

No Brasil, os principais aspectos investigados por vários estudos sobre esse processo podem ser elencados nos tópicos a seguir. A variável sistêmica "lista eleitoral" foi e é considerada desfavorável. O sistema de lista no Brasil é completamente aberto - vota-se no candidato e não numa lista fechada e ordenada previamente pelo partido. ${ }^{6}$ A lista aberta pode garantir a cota mínima de candidaturas, mas não assegura relações de causa e efeito entre maior número de candidatas e maior número de eleitas. $\mathrm{O}$ exame do processo brasileiro aponta para debilidades consideráveis, no que tange a alguns itens e requisitos elencados mais acima. Entre as principais destacam-se: a) o frágil conteúdo da legislação e, em especial, na clareza de uma norma relativa ao percentual mínimo e no que se refere às punições por eventual descumprimento: entre 1997 e 2009 a lei foi aprimorada algumas vezes, a fim de torná-la efetivamente obrigatória; b) o papel quase ausente do TSE para estimular o cumprimento da lei ou fiscalizá-la, algo que só passa a ocorrer a partir de 2010 e, mais efetivamente, a partir de $2012 ;^{7}$ c) e a mobilização dos movimentos

${ }^{6} \mathrm{O}$ sistema de lista aberta é considerado problemático em si, independentemente das cotas. Ver, entre outros, Nicolau (2006).

${ }^{7}$ Neste caso, a hipótese estaria relacionada com a eleição de uma mulher para a presidência da república e o que defino como visibilidade da ausência. 
de mulheres nos partidos mas, sobretudo, entre os chamados movimentos sociais, marcadas por fraco envolvimento para colocar na agenda pública o papel do parlamento nas formulações de políticas públicas de interesse das mulheres e o gap de gênero. As cotas em seu objetivo primeiro e direto: um mínimo de $30 \%$ de candidaturas - só foram efetivamente atingidas em 2012 para eleições municipais e em 2014 para eleições estaduais e federais. Cumprido esse patamar mínimo, as cotas não lograram atingir aquele que seria ser seu objetivo indireto, porém considerado mais relevante e pensado como causal: possibilitar a eleição de número maior de mulheres. Ao contrário, o aumento considerável de candidaturas em 2012 e em 2014 manteve a eleição estagnada, e revelou que, proporcionalmente, a taxa de sucesso das mulheres decresceu. $^{8}$

Após ficar demonstrada a inefetividade na eleição de mais mulheres, ainda que o número de candidaturas tenha crescido bastante, parte das análises que buscaram compreender esses resultados, em especial de militantes no campo político, ${ }^{9}$ esteve circunscrita ao papel dos partidos políticos, ao seu rarefeito compromisso com as políticas de cotas, notadamente, ao papel dos dirigentes partidários no recrutamento eleitoral para propiciar candidaturas mais consistentes, capazes de concorrer efetivamente. ${ }^{10}$ A complicada mediação entre norma jurídica e ação política, embora colocada, tendeu a ser analisada num único vetor. Nessa leitura, a cultura política patriarcal que ainda domina os partidos determinaria e responderia pelo problema da seleção de candidaturas (conhecida como recrutamento político) assim como dos recursos investidos em mulheres candidatas, e tenderia a responder pela quase totalidade das limitações à eficácia das cotas. Pesquisas sugeriram problemas ou limitações associadas com as chances geradas pelo sistema político e com a falta de compromissos partidários. É fato (Santos et al., 2012), mas revelaram também traços e configurações sociais que dizem algo sobre o outro vetor: os campos geradores de políticos, que podem ser considerados ainda bastante tradicionais e patrimonialista, assim como sobre a participação como "celeiro" de indivíduos interessados em política institucional. O perfil das candidaturas vitoriosas no Brasil está mais associado a alguns espaços sociais (Araújo e

\footnotetext{
${ }^{8}$ As taxas de sucesso medem a relação entre o número de candidatos lançados e eleitos. Conforme mostraram Araújo e Alves (2011) e Bolognesi (2012), as taxas de sucesso eleitoral das mulheres e a razão de chance decresceram seguidamente, à medida que as candidaturas foram aumentando.

${ }^{9}$ Declarações e artigos podem ser encontradas em diversos sites institucionais, sites de jornais de grande circulação ou ainda no site do Instituto Patrícia Galvão.

${ }^{10}$ Apesar de certa unidade nas críticas, há divergências dessas protagonistas sobre o tipo de lista eleitoral mais adequado para o Brasil.
} 
Borges, 2012; Almeida et al., 2012; Miguel et al., 2015). ${ }^{11}$ A análise desse perfil em 2014 é emblemático: candidaturas efetivas têm vetores importantes de origem em alguns caminhos: participação associativa ou política anterior por um lado, forte viés de pertencimento familista e, ainda, em trajetórias individuais de campos religiosos ou outros tipos de atividades individuais que tem crescido. ${ }^{12}$

Sem dúvida, a crítica e o foco nos partidos políticos como instituições, e nos seus dirigentes como atores dotados de agência no sentido sociológico, capazes de fazer alguma diferença, é relevante, necessária e também central. Mas é insuficiente. Aqui são indicadas, de forma breve, as razões para tal insuficiência. Insuficiente por tentar responder à pergunta "por que poucas mulheres se elegeram mesmo após as cotas" a partir de uma lógica causal, não possível de ser assumida nos termos do sistema eleitoral brasileiro de lista aberta - isto porque seria conceber o sistema como uma redoma, em que a única variável dependente seria o compromisso partidário, ao invés de uma lógica multicausal e sociológica do problema; porque tendem a acentuar, sobremaneira, o foco na "vontade política" dos dirigentes, desconsiderando outros condicionantes na interação entre a formação de chapas eleitorais e atores nos campos políticos, a partir de onde surgem e são pensados os potenciais candidatos. O recrutamento seria, assim, um processo muito dependente dos dirigentes e focado na dimensão sistêmica e interna aos partidos. Em suma, porque há também os aspectos externos aos sistemas partidários que não só sofrem, mas expressariam o estado da sociedade e do envolvimento dos atores com a política. Estes são os objetos de interesse do presente trabalho: as mediações entre os partidos e o "restante" da sociedade, seus valores e as formas como se estruturam econômica e socialmente.

Compreende-se que o trânsito entre, por um lado, partidos, e, por outro, grupos e indivíduos potencialmente aderentes e interessados em entrar na política teria um vetor de mão dupla. Envolveria, entre outros fatores, (não necessariamente determinantes e fixos), as percepções e os valores em relação ao que se define em termos gerais como cultura política, bem como as características e tendências de adesão e participação política em outros campos que não os partidos. As dinâmicas gerais que pautam os ingressos na política e pautam os partidos no momento de definir suas candidaturas revelam

\footnotetext{
${ }^{11} \mathrm{O}$ termo "candidaturas laranjas" refere-se a candidatos que são registrados apenas formalmente. ${ }^{12} \mathrm{O}$ perfil dos eleitos para o Congresso Nacional no ano de 2014 é bastante revelador desse traço: $49 \%$ dos eleitos para a Câmara dos Deputados tinham algum parente na política. Entre as mulheres eleitas esse percentual subia para pouco mais de $51 \%$.
} 
dificuldades e fragilidades de diversas ordens. Dinâmicas que interagem com os "celeiros" de possíveis competidores e, nesse sentido, expressam as estruturas sob a qual se erige a política, as crenças sociais e individuais sobre as instituições e os tipos de propensões à participação. Se isto afeta a todos, homens e mulheres, guardariam alguns diferenciais quando pensadas a partir das relações de gênero.

É certo que os capitais políticos que respondem aos interesses e necessidades de cada organização tendem a estar associados com a obtenção de vitória eleitoral. E eventualmente ter mulheres pode ser uma estratégia simpática que agrega votos. O gênero é levado em conta eventualmente, desde que implique ou responda a essas estratégias contextuais e à engenharia eleitoral dos partidos (Álvares, 2004; Sacchet, 2009). Associações entre esses fatores e dimensões compõem essas rotas e são parte da compreensão sobre o ponto de chegada: a eleição (Fox e Lawless, 2012; Gaxie, 2012). Assim, importa saber como os valores preponderantes, existentes numa sociedade num dado momento ou período, e relacionados com o que se define como cultura política, influenciam as condições de participações políticas; como interferem na formação de potenciais capitais para disputas políticas; e, mais relevante para o propósito desta investigação, como o gênero recorta e ajuda a compreender a forma como essas propensões e inserções ocorrem entre homens e mulheres. Além dos vários estudos que se dedicam ao problema, como por exemplo os de Borba e Ribeiro (2010), Almeida et al. (2012) e Miguel et al. (2015) entre outros, algumas pistas pelo viés dos valores podem ser aqui indicadas.

Valores, formas de inserção, associação e atitudes, ou o que alguns chamam de cultura política são aspectos influenciadores e interferem na participação política, inclusive nos componentes institucionais dos sistemas políticos. Por isso, faz sentido aqui a proposição de Urbinati (2006), para quem a representação é uma forma de presença que possui certa autonomia - o processo eleitoral em si e o sistema político e partidário - mas pode ser pensada como um contínuo de ação política (Urbinati, 2006).

Formas de participação política não necessariamente levam a envolvimentos ou interesse por representação. De igual modo, a disposição para a ação política através do ingresso na esfera da representação política nem sempre está associada com trajetórias prévias de participação. Mas participação é parte do que se concebe como democracia, na dimensão participativa em si e também na representativa. A participação é esse contínuo proposto acima, inclusive porque trata da" [...] ação de cidadãos comuns com o objetivo de influenciar alguns resultados políticos” (Brady, 1999, p. 737 apud Borba, 2012). 
A participação é diversificada e engloba o voto, a mobilização para tal, assim como atividades comunitárias e atividades individuais, em ações de protesto ou pressões por determinadas demandas e apoios a causas específicas (Brady, 1999, p. 737 apud Borba, 2012). Pode ser individual, cidadã e coletiva. Sua natureza pode ser diretamente social, quando o foco, sem deixar de ser político, está voltado para o exercício da participação não imediatamente vinculada à democracia representativa, ainda que em espaços institucionais; pode ocorrer, inclusive, como representação, junto ao governo e suas instâncias, para além das fronteiras da representação legislativa (Pogrebinschi e Santos, 2011; Gohn, 2003; Arretche, 1999). E ainda, as dimensões da participação podem ter orientações e motivações políticas, mas sem vínculos diretos com a representação (Borba, 2012).

O campo político que ultrapassa a representação e segue como esse contínuo proposto e brevemente discutido acima não é neutro. As condições e posições estruturalmente ocupadas pelos indivíduos, os interesses dos atores e grupos, a socialização e as condições de reprodução da vida afetam as disposições para indivíduos se interessarem e se envolverem na política, sobretudo a política institucional, são mutáveis e são construídas. Remete aos traços e características destacados por Bourdieu, para quem, embora autônomo no sentido de parâmetros de identificação, as condições que permitem o acesso ao campo são sociais e históricas e que "[...] essas propensões, essas aptidões, essas capacidades são muito desigualmente distribuídas, não por natureza [...] mas porque existem condições sociais de acesso à política" (Bourdieu, 2011, p. 196). Tais condições têm na clivagem de gênero um marcador relevante. Este marcador de desigualdades de condições de participação opera, também, como medida da promessa de justiça embutida nos modelos da democracia representativa. De fato, tem sido no gap de gênero, recorrente e com padrões empiricamente identificáveis, que essas aporias vêm insistentemente se manifestando e de forma considerável.

Nesses termos, mais do que um problema interno aos procedimentos políticos eleitorais, os determinantes da participação, inclusive na representação, se associam às condições de participação política e social e se vinculam a elementos da socialização, ainda que sejam moldados por outros condicionantes, inclusive as desigualdades socioeconômicas (Fox e Lawless, 2012). Este ponto interessa de modo particular ao presente trabalho, pois essa dimensão da socialização envolve tanto aquilo que denominamos de valores, como as formas como esses valores orientam as disposições dos indivíduos para possíveis participações. Por isso, ainda que sair dos fatores institucionais e mapear as ações e intenções dos dirigentes 
partidários seja crucial, faz-se necessário, também, compreender como essa socialização opera previamente no envolvimento dos indivíduos com a política, a partir do campo dos valores e daquilo que definimos como cultura política.

\section{Valores e cultura política como problemas da participação democrática: algumas considerações}

$\mathrm{O}$ conceito que parece ser mais apropriado para pensar os valores, direcionados para o tema proposto, é o de "cultura política". Não se desconsidera todas as críticas dirigidas aos seus criadores (Almond e Verba, 1989), em especial, quanto à natureza normativa do conceito, apenas focada na política stricto sensu e engessada em relação às dinâmicas sociais que poderiam influenciar e transformar a própria cultura política. Esse conceito foi revisto e ampliado de sentido e ângulos mais amplos, inclusive por autores brasileiros (Moisés, 1995; Kuschnir e Carneiro, 1999; Borba, 2005; Lena Júnior, 2012). Kuschnir e Carneiro (1999, p. 2), por exemplo, compreenderam que a cultura política trata de "[...] conjunto de atitudes, crenças e sentimentos que dão ordem e significado a um processo político, pondo em evidência as regras e pressupostos nos quais se baseia o comportamento de seus atores". A característica processual, com as dimensões da prática e da experiência são também importantes elementos formadoras de valores (Lena Júnior, 2012). Por último, há sua utilidade analítica de "[...] contribuir para a explicação do comportamento político dos indivíduos, pesquisar as crenças, identidades e valores dos indivíduos, destacando a forma como os valores culturais são componentes endógenos da tomada de decisão" (Borba, 2005, p. 151). Valores morais e políticos que se inserem nessa cultura política são também compostos de e por percepções sobre atributos e lugares mais ou menos apropriados, segundo a pertença de sexo e o gênero.

\section{Valores, crenças e tendências de participação política: algumas pistas para incluir o gênero}

Pesquisas indicam que os brasileiros estariam se tornando menos tradicionais e mais modernos em relação aos valores em geral, menos orientados a ações por sobrevivências e mais orientados a ações de bemestar pessoal, conforme mostra a tabela 2 (WVS, 2015). Entre 1996 e 2014 o índice que mede esses tipos de valores foi alterado, indicando certa associação entre mudanças nos valores e nas condições socioeconômicas. Ao lado disso, verifica-se a tendência à maior igualdade nos valores de gêneros entre os sexos (Américabarômetro, 2013; WVS, [vários anos]). 
Tabela 2. Alterações nos índices de valores no Brasil no mapa cultural do World Values Survey, 1996-2014

\begin{tabular}{ccc}
\hline Ano & $\begin{array}{c}\text { Valores tradicionais } \boldsymbol{v s} \\
\text { valores seculares }\end{array}$ & $\begin{array}{c}\text { Valores de sobrevivência } \boldsymbol{v s} \\
\text { valores individuais }\end{array}$ \\
\hline 1996 & $-1,2$ & $-0,8$ \\
2014 & $-0,1$ & 0,2 \\
\hline
\end{tabular}

Fonte: World Value Survey, 2015.

Os dados do Consórcio Latinobarômetro também apontam nessa direção. Os vinte anos cobertos por pesquisas desse Consórcio revelam, contudo, algumas aporias que podem ter efeitos sobre a participação política dos indivíduos, notadamente, em se tratando de participação das mulheres. No contexto latino-americano a situação do Brasil tende a ser preocupante. Os brasileiros estão abaixo da média em relação a valores democráticos em muitos aspectos. ${ }^{13}$ Observa-se um padrão de envolvimento político baixo, baixa confiança nas instituições políticas e, inversamente, elevada confiança em instituições como a igreja e mídia. Essas tendências se apresentam mais acentuadas para as mulheres, conforme se pode observar nos gráficos 1 e 2 .

$\mathrm{O}$ apoio à democracia como valor tem crescido na região. $\mathrm{O}$ crescimento é relativamente maior entre as mulheres. Entre os países da América Latina o Brasil, não obstante o crescimento, tende a apresentar percentuais muito baixos nesse item. A democracia como valor se expressa, também, em dois outros dados: queda nas preferências por formas autoritárias de governo (21\% em 1995 e 16,2\% em 2015), e na indiferença à política. Mas há no país uma queda no grau de satisfação com a democracia, refletindo, provavelmente a insatisfação que se materializou a partir das manifestações de 2013. O Brasil apresenta um dos mais elevados índices de insatisfação, e mulheres apresentam níveis de insatisfação um pouco maior do que dos homens. Em uma escala de percepção de quão democrático é o país, segundo o sexo, apenas $9,1 \%$ dos homens e $6,2 \%$ das mulheres consideraram o Brasil muito democrático.

No quesito confiança nas instituições em geral, em 2015, em comparação com 1995, a igreja seguia como líder. Como pesquisas têm mostrado, mulheres

\footnotetext{
${ }^{13}$ São apresentadas vinte perguntas sobre o grau de confiança e a satisfação com as instituições, a confiança individual, a predisposição para eventuais participações e a percepção sobre a importância do envolvimento. Nas tabelas cada enunciado foi transformado em sigla. São apresentados apenas as somas de respostas de apoio, com as categorias de "Muito" e "Um pouco" no gráfico 1; ou "Apoio" e "Participou" no gráfico 2.
} 
confiam mais do que homens nessa instituição, mas no período houve ligeiro decréscimo, ao passo que entre os homens houve ligeiro crescimento da confiança na igreja. Ainda assim, essa foi a instituição que respondeu pelos patamares mais elevados entre todas as instituições perguntadas.

Já a confiança nas instituições consideradas bases da democracia representativa segue muito baixa, e decresceu no período mais recente, em todos os estratos. De fato, algumas dessas instituições são as mais mal avaliadas como dignas de confiança. O menor patamar de confiança atinge os partidos políticos, conforme pode ser visto na tabela 3 . Apenas $15,4 \%$ dos homens e $17,1 \%$ das mulheres na região informaram ter total ou alguma confiança em partidos políticos. O gráfico 1 mostra que essa confiança tende a ser menor entre as mulheres e, comparativamente a 1995, decresceu no ano de 2015. Esse é um dado deveras preocupante. Há certa consistência no padrão de baixa confiança, mas a comparação nas décadas mostra o aumento desse descrédito. O sentimento de proximidade com partidos políticos, outra questão que opera como indicador de envolvimento, também é baixo e se manteve praticamente o mesmo ao longo dos 20 anos analisados. No ambiente de distanciamento geral, as mulheres apresentaram um ligeiro incremento nessa percepção de proximidade. Há que se investigar dois possíveis fatores intervenientes nesse sentido: a eleição de uma mulher para a presidência, um fator simbólico, e as políticas sociais que marcaram as décadas de 2000 e o início desta década. De todo modo, salta à vista o contraste entre a avaliação sobre partidos, congresso e governo, ao passo que depois da igreja, as forças armadas, são as instituições bem avaliadas.

Os sindicatos são uma das organizações não integrantes do sistema político com papel tradicionalmente político e formador de lideranças e potenciais competidores eleitorais. No período, a confiança nos sindicatos registrou decréscimo entre os homens e se manteve estável entre as mulheres. $\mathrm{O}$ aumento da força de trabalho feminina no período e a queda no emprego precário registrado nas duas últimas décadas podem responder por essa tendência. A sindicalização está associada com empregos menos precários e mais estáveis. Durante a década de 2000 ocorreu um aumento da sindicalização, no número de filiados e das taxas de sindicalização maior entre trabalhadoras. O incremento do número de sócios masculinos foi de $26,7 \%$, ao passo que o feminino foi de 109,4\% (Pichier, 2011, p. 41). Contudo, se comparativamente a alguns outros países o nível de confiança em sindicatos no Brasil é mais elevado, isso significa um percentual de $25 \%$ de confiança, ao passo que a confiança na igreja é cerca de $70 \%$, e maior entre as mulheres do que entre os homens. 
Tabela 3. Níveis de confiança e variação por instituição entre os anos de 1995 e 2015 - Brasil.

\begin{tabular}{lcc}
\hline & Mínimo & Máximo \\
\hline Partidos & 13 & 36 \\
Congresso & 21 & 40 \\
Poder Judiciário & 24 & 40 \\
Governo & 28 & 45 \\
\hline
\end{tabular}

Fonte: Latinobarômetro, 2015.

Gráfico 1. Percentuais de confiança em instituições, por ano e sexo, Brasil, 1995 e $2015^{\text {(a) }}$

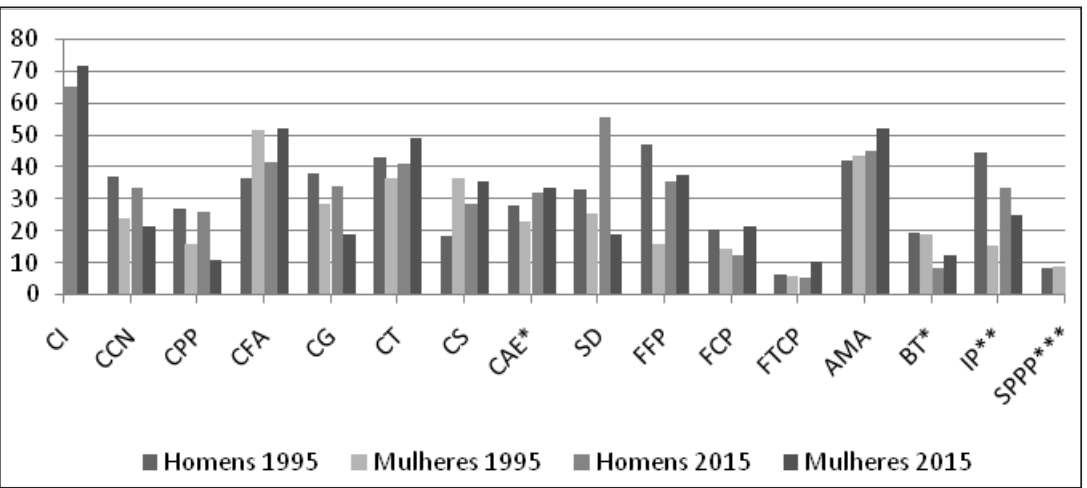

(a) Agregados apenas "muita confiança" e "alguma confiança".

* Perguntas feitas em 1995 e 2005; ** Pergunta feita em 1995 e 2013; *** Pergunta feita em 1995 e 2003.

Legenda: CI - Confiança na igreja; CCN - Confiança no Congresso Nacional; CPP - Confiança nos partidos políticos; CFA - Confiança nas Forças Armadas; CG - Confiança no governo; CT - Confiança na televisão; CS - Confiança nos sindicatos; CAE - Confiança nas associações empresariais; SD - Satisfação com a democracia; FFP - Frequência com que fala de política; FCP - Frequência com que trata de convencer alguém politicamente; FTCP - Frequência que trabalha para candidato ou partido; AMA - Assistir a manifestações autorizadas; BT - Ação política de bloquear o tráfego; IP - Interesse na política; SPPP - Sentimento de proximidade em relação a um partido político.

Fonte: Latinobarômetro, 1995 e 2015. Elaboração própria.

A confiança ou desconfiança não implica, por sua vez, descrença no instrumento considerado mais relevante para o exercício da delegação na democracia representativa: o voto. A crença no voto tem crescido e no Brasil cresceu comparativamente mais entre as mulheres do que entre os homens, conforme pode ser visto no gráfico 2 . 
Gráfico 2. Percentuais de confiança em instituições e valores políticos, por ano e sexo, Brasil, 1995 e $2015^{\text {(a) }}$

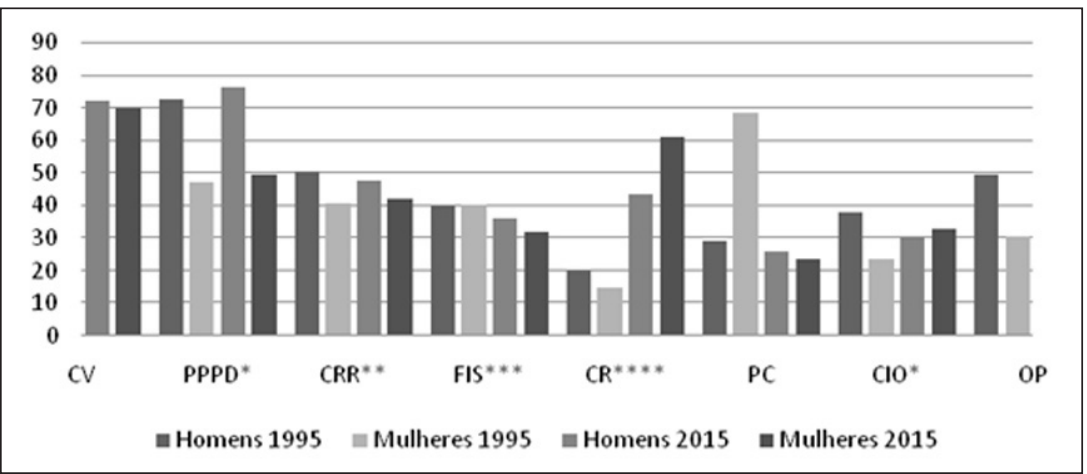

(a) Perguntas dicotômicas. Dados relativos à concordância com o enunciado.

* Perguntas feitas em 1995 e 2013; ** Pergunta feita em 1995 e 2009; *** Pergunta feita em 1995 e 2003; **** Pergunta feita somente em 1995.

Legenda: CV - Confiança no voto; PPPD - Papel dos partidos políticos; CRR - Democracia resolve problemas; FIS - Ingresso em sindicato se tivesse oportunidade; CR - Crença em representantes; PC - Política complicada; CIO - Crença na igualdade de oportunidade; OP - Opinião política.

Fonte: Latinobarômetro, 1995 e 2015. Elaboração própria.

O envolvimento com a política em geral é aqui ilustrado através de algumas perguntas contidas nos dois gráficos. Três perguntas remetem à frequência com que o respondente desenvolve algum tipo de ação: frequência com que trabalha para partidos políticos ou um candidato; frequência com que conversa com amigos sobre política; e frequência com que tentou convencer pessoas em relação à política. Esses índices são baixos em geral, mas comparativamente as mulheres tenderam a se envolver mais do que os homens. O envolvimento com candidaturas eleitorais, contudo, é o que apresentou menores percentuais. $\mathrm{O}$ convencimento de outras pessoas em relação a uma posição ou proposta política é atualmente considerado pela literatura como uma forma de interesse e envolvimento político. Na região, 17,8\% dos homens e 13,7\% das mulheres disseram ter tentado convencer alguém sobre suas posições e propostas. No Brasil, esses percentuais alcançaram $22,7 \%$ para a população em geral, $23,8 \%$ entre os homens e $21,5 \%$ entre as mulheres. Já a frequência com que os entrevistados falam com os amigos sobre política aponta que, na região, $33,9 \%$ o fazem e entre os brasileiros essa prática foi reportada por $32,9 \%$ dos respondentes. Os padrões desse tipo de envolvimento entre homens e mulheres variam pouco, mas é notável que seja entre as mulheres que tenham crescido mais as respostas associadas com maior frequência. 
A crença nas instituições também não é idêntica ao interesse pela política e isto fica claro na diferença entre tipos de envolvimento ou de participação. Os padrões institucionais e culturais dos países parecem contar bastante e tendem a aproximar homens e mulheres de um mesmo país. ${ }^{14}$ Alguns tipos de envolvimento relevantes para a participação, e em relação aos quais as mulheres, tradicionalmente, foram identificadas como ausentes, e por isto, apáticas, têm apresentado percentuais crescentes de envolvimento, ainda que não se tratem de índices mais robustos. A ideia de apatia e de desinteresse das mulheres em relação à política vai sendo desconstruída inclusive empiricamente, na medida em que variáveis podem ser mais bem analisadas, seja em comparação temporal ou ainda, entre países. Mas a cidadania liberal parece não estar consolidada, também, se nos basearmos nas crenças sobre a igualdade de oportunidades como valor. Essa crença diminuiu entre os homens e se manteve estável, e baixa, entre as mulheres.

Em síntese, as instituições consideradas basilares para a democracia e, portanto, relevantes para que as pessoas pensem em participar ou interferir são as que apresentam os mais baixos índices de confiança. Os partidos seguem, nesses 20 anos, como a instituição com índices mais baixos de apoio (ver tabela 3). O relatório do Latinobarômetro sugere uma aporia essencial para pensar os desafios da participação, tomando por base os valores dos entrevistados ao identificar que "[...] contraste la democracia produce instituciones en las cuales la gente no confia” (Relatório Latinobarômetro, 2015, p. 7).

\section{Fatores sociodemográficos que afetam os valores e as possibilidades de participação à luz das mediações de gênero}

O sexo não apresenta significância como variável preditora ou identificadora de maior ou menor apoio à democracia, não obstante os percentuais ligeiramente diferenciados apresentados nos dados selecionados e em outros dados da pesquisa (Latinobarômetro, 2015). A educação é a variável chave para valores mais igualitários, no Brasil e na América Latina em geral. $\mathrm{O}$ efeito sobre o sexo ocorre apenas quando a educação é considerada. A escolaridade, associada com desigualdade é, sobretudo, um indicador de valores mais ou menos igualitários e isto vem sendo comprovado por várias pesquisas. Mulheres que acusam menor nível de apoio à democracia têm escolaridade mais baixa.

A confiança interpessoal se revelou baixa e a confiança nas instituições convencionais de associativismo, tais como sindicatos, também. Entre países

\footnotetext{
${ }^{14}$ Conforme dados do projeto e não discutidos neste trabalho (cf. www.latinobarometro.org).
} 
da América Latina os níveis de confiança interpessoal dos brasileiros são surpreendentemente baixos ( $8 \%$ contra $22 \%$ na Argentina e $18 \%$ no Peru, por exemplo). ${ }^{15}$ Em geral esses percentuais tendem a ser mais baixos entre as mulheres, porém tal diferença não é significativa em termos estatísticos. Isso surpreende, inclusive, se considerarmos as representações correntes quanto à sociabilidade, amabilidade e espírito de convivência dos brasileiros. Contudo, há associação entre confiança interpessoal e geração. Segundo o relatório, não há diferenças sociodemográficas significativas que expliquem esse comportamento, e o único preditor de maior propensão à confiança é a idade: quanto mais velho, maior a confiança.

O ponto a destacar para este trabalho é a relação entre desconfiança, propensões à participação e formação de lideranças e capitais políticos. A desconfiança entre os mais jovens poderia ser um obstáculo ao envolvimento, ademais do problema da legitimidade da política. ${ }^{16}$ As trajetórias de parte dos representantes são marcadas por envolvimentos prévios com práticas e formas de inserção em espaços políticos comunitários, de classe, entre outros espaços. A indiferença teria impacto sobre a construção de carreiras, formação de lideranças e capital político com base em trajetórias e experiências. $\mathrm{O}$ déficit de participação política por sexo antecede esses contextos recentes e, para as mulheres, decorre de causas históricas; mas se ancora em condições perpetuadoras e reprodutoras de menores chances de inserção social. Além disso, a desigualdade social tende a afetar as predisposições para a participação em democracias representativas. Assim, considerando a ideia e o valor da participação como algo constitutivo das democracias modernas independentemente de seu grau efetivo -, tenderia a haver maior dificuldade incremental para as mulheres. Níveis elevados de desconfiança em relação à política estariam associados com elevados níveis de desigualdade e com luta por sobrevivência. As mulheres apresentam situações mais desiguais em termos econômicos, de renda e de encargos familiares.

Aos fatores elencados acima se somam as já discutidas condições históricas e estruturantes das relações de gênero e que perduram como impactos, pois conforme Chapman (1993, p. 23) assevera, "[...] qualquer que seja o atributo necessário para a presença no mundo público, os homens terão mais do que as mulheres [...]". Assim, embora as mulheres apresentem, em alguns aspectos, maior propensão à participação no período atual, a desconfiança institucional e política pode ter mais impactos sobre as disposições em ingressar em espaços

\footnotetext{
${ }^{15}$ Essa mesma tendência está presente nos dados do WVS (2016).

${ }^{16}$ Embora seja também potencial formador de insatisfações que geram rupturas.
} 
de disputa. Estamos falando, pois, de reprodução de desigualdades à parte dos contextos. Se a predisposição baixa, ou se é baixa, e se isto se reduz inclusive em certos perfis e contextos, então as possibilidades incrementais de superar o gap de presença por gênero se elevariam.

\section{Algumas evidências sobre a relação entre valores de gênero, participação e divisão sexual do trabalho}

Vários estudos mostram que a valorizada premissa liberal do "livre arbítrio" e da autonomia de escolhas é parte de uma inadequação que baseia valores e também percursos estruturantes da relação analisada em valores de gênero como clivagem estruturante. Seguem algumas evidências que ajudam a pensar a articulação proposta. Estudo do América Barômetro (2012) tentou captar interveniências de valores de gênero em algumas formas de inserção política. Procurou-se saber, de forma mais específica, se e de que maneira variáveis socioeconômicas estariam associadas com os papéis de gênero, as atitudes e o envolvimento político (Hinton et al., 2012). ${ }^{17}$ Os autores exploraram aspectos associados à formação de lideranças a partir de recorte importante: a condição de atividade econômica das mulheres ativas no mercado de trabalho ou donas de casa. Os resultados apontam que nas questões envolvendo inserção política, participação, interesse e apoio a protestos, o engajamento das mulheres que possuíam trabalho assalariado foi maior do que entre as mulheres sem trabalho assalariado. Os papéis de gênero desempenhados pelas mulheres se relacionam e afetam a participação e o exercício da liderança política: mulheres que não trabalham participam mais em associações religiosas e associações de pais em comparação com os homens em geral e em comparação com as mulheres que trabalham. $\mathrm{O}$ estudo mostra que, na política, as maiores desigualdades de gênero estão associadas com a postulação às candidaturas e à ocupação de cargos políticos. A investigação concluiu que há uma convergência entre as taxas de participação eleitoral de homens e mulheres no âmbito do período investigado, ou seja, desde 2004 até 2012. No entanto, e esta chave analítica é a que interessa de forma particular a este trabalho,

[...] Algunas investigaciones académicas han mostrado que gran parte de las desigualdades en participación política se deben a las desigualdades existentes en la división del trabajo dentro del hogar (Hinton et al., 2012, p. 51).

\footnotetext{
${ }^{17}$ Várias perguntas foram incluídas na rodada relativa ao ano de 2012 pelo Barómetro das Américas
} 
A pesquisa tendeu a confirmar maior peso na relação entre desigualdades socioeconômicas e desigualdades na participação, em comparação com a variável "discriminação de gênero" (Hinton et al., 2012, p. 51). O ativismo político-eleitoral foi medido pela participação em campanhas através de perguntas sobre o trabalho de persuasão política. O efeito do trabalho assalariado foi significativo no envolvimento político. A diferença entre mulheres que trabalham e os homens em geral foi menor do que entre mulheres com trabalho remunerado e aquelas sem trabalho remunerado. As donas de casa apresentaram menores porcentagens de tentativas de convencer outras pessoas de suas posições e trabalharam menos em campanhas políticas, em comparação com as mulheres que trabalham. Tais correlações foram encontradas também para outra forma de participação: a de participação em protestos. A condição de trabalhadora surge como fator formador de sociabilidade, troca de opiniões e autonomia para participar da política; o trabalho remunerado surge como fator estimulador da participação.

No entanto, convém lembrar que, diferente da situação dos homens, o trabalho remunerado das mulheres, quer em espaços públicos ou privados, não ocorre desprovido de vínculos com os imperativos familiares de cuidado e de responsabilidades domésticas. O tempo tende a operar como elemento de contenção da participação feminina em dois sentidos. Primeiro como requisito válido para todos os que querem participar da política. Segundo, como condicionante direto e moral para as mulheres que possuem famílias e, em se interessando por maior inserção política, necessitariam reduzir suas atividades nesses espaços. Dilema que de antemão não está colocado para os homens.

Nesse primeiro sentido, convém remeter o leitor à tipologia de atributos para a participação política proposta por Verba et al. (1995 apud Borba, 2012). A variável tempo integra os requisitos considerados relevantes para a participação (ver quadro 1). Na tipologia são listadas nove formas de participação e em oito dessas formas o tempo é incluído como requisito para tais práticas. ${ }^{18} \mathrm{O}$ requisito do tempo permite falar da injustiça do estreitamento indireto da participação. As "escolhas" e "opções" sobre a participação e o envolvimento político seriam termos mais distantes para as mulheres do que para os homens.

\footnotetext{
${ }^{18}$ Sem entrar no mérito das polêmicas e críticas, a tipologia é ilustrativa do que o texto está propondo.
} 
Quadro 1. Os atributos das atividades políticas

\begin{tabular}{|l|c|c|c|}
\hline \multicolumn{1}{|c|}{ Atividade } & $\begin{array}{c}\text { Capacidade } \\
\text { para transmitir } \\
\text { informação }\end{array}$ & $\begin{array}{c}\text { Variação } \\
\text { no volume }\end{array}$ & Requerimentos \\
\hline Voto & Baixo & Baixo & Tempo \\
\hline Trabalho de campanha & Misto & Alto & Tempo e dinheiro \\
\hline Contribuição para campanha & Misto & Alto & Tempo e dinheiro \\
\hline Protesto & Alto & Médio & $\begin{array}{c}\text { Tempo, habilidade } \\
\text { e dinheiro }\end{array}$ \\
\hline Contato com agentes públicos & Alto & Médio & Tempo \\
\hline Trabalho informal na comunidade & Alto & Alto & Tempo, habilidades \\
\hline Membro de um clube politico local & Alto & Alto & Tempo e habilidade \\
\hline $\begin{array}{l}\text { Filiação a uma organização } \\
\text { partidária }\end{array}$ & Médio & Alta & $\begin{array}{c}\text { Tempo, habilidades } \\
\text { e dinheiro }\end{array}$ \\
\hline Contribuição a uma causa política & Misto & Muito alto & Dinheiro \\
\hline
\end{tabular}

Fonte: Verba et al., 1995, apud Borba, 2012.

Associado mais diretamente ao tempo doméstico pode-se sugerir (com base em várias pesquisas) que seus efeitos são diretos, como inibidores efetivos de participação; e indiretos, decorrentes não tanto dos valores sobre participação, mas de valores de gênero afetos à dualidade espaços públicos vs espaços privados. Seriam também inibidores que operam como seletividade moral da participação, já que implicariam escolhas de dedicação de tempo à política em detrimento da dedicação esperada para a família (Fox e Lawless, 2012). A título de ilustração em relação ao tema, a essas possíveis implicações e ao contexto brasileiro, três tipos de dados sobre o país são apresentados nas tabelas 4,5 e 6 . A tabela 4 apresenta a distribuição da sindicalização por sexo, o número de horas dependidas com o trabalho doméstico por população ocupada e com mais de 40 horas de trabalho. A tabela 5 apresenta dados da Pnad 2014 sobre a distribuição da média de horas nas atividades domésticas e de trabalho remunerado no Brasil, e mostra um gap de jornada doméstica ainda maior. Já a tabela 6 mostra como essas desigualdades na distribuição do tempo e nas responsabilidades domésticas se estruturam desde a infância, sugerindo que os valores de gênero ainda desiguais tendem a afetar diferentemente as chances dos indivíduos nos espaços públicos. 
Tabela 4. Condições de trabalho, sindicalização e tempo médio dedicado aos afazeres domésticos no Brasil, 2009

\begin{tabular}{lcc}
\hline \multicolumn{1}{c}{ Situação } & Homens (\%) & Mulheres (\%) \\
\hline Distribuição do emprego com carteira assinada & 58,6 & 41,4 \\
Taxa de sindicalização & 18,6 & 16,6 \\
$\begin{array}{l}\text { Proporção da sindicalização segundo o sexo } \\
\begin{array}{l}\text { Tempo médio semanal dedicado às atividades } \\
\text { domésticas - pessoas ocupadas que trabalham entre }\end{array}\end{array}$ & 60,1 & 30,9 \\
40 e 44 horas, por sexo & 14,0 & 18,3 \\
\hline
\end{tabular}

Fonte: Dieese, 2011 (dados relativos a 2009).

Tabela 5. Média de horas semanais dedicadas ao trabalho pago, trabalho doméstico e média total, segundo o sexo, Brasil e região sudeste, 2013

\begin{tabular}{lcccccccccc}
\hline & \multicolumn{3}{c}{$\begin{array}{c}\text { Média de horas trabalhadas } \\
\text { no trabalho principal }\end{array}$} & \multicolumn{2}{c}{$\begin{array}{c}\text { Média de horas gastas em } \\
\text { afazeres domésticos }\end{array}$} & \multicolumn{3}{c}{ Jornada total } \\
\cline { 2 - 10 } & Total & Homem & Mulher & Total & Homem & Mulher & Total & Homem & Mulher \\
\hline $\begin{array}{l}\text { Brasil } \\
\text { Região } \\
\text { Sudeste }\end{array}$ & 39,2 & 41,8 & 35,7 & 16,2 & 9,8 & 20,6 & 55,4 & 51,6 & 56,4 \\
\hline
\end{tabular}

Fonte: Pnad-IBGE, 2014.

Tabela 6. Proporção da população de crianças, adolescentes e jovens entre 10 e 29 anos que cuidavam de afazeres domésticos na semana de referência, Brasil, 2013

\begin{tabular}{ccccc}
\hline \multirow{2}{*}{ Faixa etária } & \multicolumn{2}{c}{ Homens } & \multicolumn{2}{c}{ Mulheres } \\
\cline { 2 - 5 } & \% que cuidava & $\mathbf{n}$ - médio de horas & \% que cuidava & no médio de horas \\
\hline $10-15$ & 37,6 & 7,7 & 68,5 & 12,2 \\
$16-24$ & 38,8 & 9,0 & 80,7 & 18,8 \\
$25-29$ & 44,5 & 9,7 & 86,8 & 23,6 \\
\hline
\end{tabular}

Fonte: Pnad-IBGE, 2014.

Em suma, a participação política tende a ser afetada por valores sob diversos ângulos, inclusive aqueles que operariam como filtros seletivos anteriores à própria participação. $\mathrm{O}$ processo definidor de quem se habilitará a ser elite da política já é em si um filtro. Fox e Lawless (2012) apresentaram largas evidências de como o gênero conta e muito nesse filtro. Segundo as autoras, isso se explicaria, inclusive, porque no momento das eleições 
propriamente dito, o perfil de quem é eleito não destoa muito segundo o gênero: porque há uma dupla filtragem entre as mulheres. Desse modo, a escassez de potenciais candidatas e de interessadas em geral em se envolver com política institucional se explicaria por outra entrada. Esta é também associada com os valores de gênero, e fariam com que medidas avaliativas de relação custobenefício em relação à participação fossem marcadas por somas de camadas de descrença, dificuldades objetivas e mensuráveis e propensões a priorizar seus "espaços naturais".

\section{Conclusão}

Este trabalho analisou a relação entre participação política, valores e apoio à democracia para compreender se e como essas conexões ajudam a explicar o gap de gênero na política brasileira, para além dos fatores mais diretamente mensuráveis e identificados no âmbito do sistema político e partidário. $\mathrm{O}$ campo no qual as políticas de cotas operam, como medidas de "caminho curto" assim como os estímulos à inserção das mulheres não são campos vazios, ou páginas em branco. Nesse cenário, a participação sociopolítica tende a ser relevante como resultante de crenças na possibilidade de intervenção política. E isto tende a incidir sobre predisposições para participar. Ademais de ser um componente da ideia de democracia, a participação pode gerar efeito duplo: ao existir como forma de pressão ou de controle social pode também ser gerador de inserção política. A participação pode também ser afetada pelas crenças e expectativas sobre a capacidade e os caminhos da política em resolver questões de interesse dos potencias participantes. Nesse sentido, pelos valores e pela cultura política.

Procurou-se compreender algumas das possíveis razões para os baixíssimos padrões de elegibilidade das mulheres brasileiras em relação a cargos eletivos. Isto foi feito a partir da discussão de aspectos que não se encontram nas fronteiras do sistema político, mas os compõem. Nesse sentido, foram explorados possíveis filtros de gênero, ou em razão de gênero, que operam como inibidores de participação antes mesmo dos processos políticos em si, derivados de crenças e descrenças ou de seletividades decorrentes de valores que dividem espaços, prioridades e motivações.

Há evidências de deslocamentos nos valores menos tradicionais no Brasil. De outra parte, as questões selecionadas no latinobarômetro, abarcando vinte anos de pesquisas mostram cenário dúbio em se tratando da participação. Foi discutido e sugerido que, em termos incrementais, isto pode produzir efeitos cumulativos sobre as desigualdades de gênero na política, embora contextos e contingências possam alterar essas tendências. Apoio à democracia 
e insatisfação com seu funcionamento são dois elementos relevantes e recortados pelo gênero.

Encontrou-se para o caso brasileiro cenários contraditórios: valores que indicam um grau de modernização e de desenvolvimento da democracia e obstáculos decorrentes de desconfiança a esse processo. Do ponto de vista das instituições tais obstáculos tendem a operar reproduzindo os padrões de inserção existentes. A intercessão com imperativos associados à divisão sexual do trabalho e à reprodução de relações de gênero menos igualitárias, operariam como filtros de seletividade que se antecipariam às condições de participação. Os dados mostraram que a divisão sexual de espaços e a esfera privada da família tendem a ser impeditivos objetivos, ademais de valorativos.

Nesse contexto, medidas de ação afirmativa, inclusive na política, podem jogar papel relevante para estimular as mulheres à participação. $\mathrm{O}$ caso do Brasil surge como mais complexo diante de sinais que não são particulares ao país, estão presentes em vários países da região: apoio e crença na democracia em abstrato, mas descrença e desconfiança em relação aos canais concretos por onde esta democracia se viabiliza. Ao que parece, os deslocamentos (ou ausência de deslocamento com engessamento) das mulheres também respondem a essas limitações, entre apoio e participação e envolvimento direto na política.

\section{Referências}

ALMEIDA, Carla; LÜCHMANN, Lígia; RIBEIRO, Ednaldo. Associativismo e representação política feminina no Brasil. Revista Brasileira de Ciência Política, n. 8, p. 237-263, $2012<10.1590 /$ S0103-33522012000200009>.

ALMOND, Gabriel A.; VERBA, Sidney. The civic culture: political attitudes and democracy in five nations. Princeton: Princeton University Press, 1989 [1963].

ÁLVARES, Maria Luzia Miranda. Mulheres na competição eleitoral: seleção de candidaturas e o padrão de carreira política no Brasil. Rio de Janeiro: Iuperj, 2004. (Tese de doutorado).

ARAÚJO, Clara. Rotas de Ingresso, trajetórias e o acesso das mulheres ao legislativo: um estudo comparado entre Brasil e Argentina. Revista Estudos Feministas, v. 18, n. 2, p. 567-584, $2010<10.1590 /$ S0104-026X2010000200016>.

ARAÚJO, Clara; ALVES, José Eustáquio Diniz. Impactos de indicadores sociais e do sistema eleitoral sobre as chances das mulheres nas eleições e suas interações com as cotas. Dados, v. 50, n. 3, p. 535-577, $2007<10.1590 /$ S0011-52582007000300004>.

ARAÚJO, Clara; ALVES, José Eustáquio Diniz. Participation of women in the elections of 2002, 2006 and 2010: the quota policy and the Brazilian electoral system. In: Adriana Piatti-Crocker (org.). Diffusion of gender quotas in Latin America and beyond: advances and setbacks in the last two decades. New York: Peter Lang, 2011. 
ARAÚJO, Clara; BORGES, Doriam. O gênero, os elegíveis e os não-elegíveis: uma análise das candidaturas para a Câmara Federal em 2010. In: José Eustáquio Diniz Alves; Céli Regina Jardim Pinto; Fátima Jordão (orgs.). Mulheres nas eleições 2010. Rio de Janeiro: ABCP $\backslash \mathrm{SPM}, 2012$.

ARAÚJO, Clara; GARCÍA QUESADA, Isabel. Latin America: the experience and the impact of quotas in Latin America. In: Drude Dahlerup (ed.). Women, quotas, and politics. New York: Routledge, 2006.

ARCHENTI, Nélida; TULA, María Inés. Mujeres y política en América Latina: sistemas electorales y cuotas de gênero. Buenos Aires: Heliasta, 2008.

ARRETCHE, Marta. Políticas sociais no Brasil: descentralização em um estado federativo. Revista Brasileira de Ciências Sociais, v. 14, n. 40, p. 111-141, 1999 $<10.1590 /$ S0102-69091999000200009>.

BOLOGNESI, Bruno. A cota eleitoral de gênero: política pública ou engenharia eleitoral? Revista Paraná Eleitoral, v. 1, n. 2, p. 113-129, $2012<10.5380 /$ pr\%20 eleitoral.v1i2.42736>.

BORBA, Julian. Cultura política, ideologia e comportamento eleitoral: alguns apontamentos teóricos sobre o caso brasileiro. Opinião pública, v. 11, n. 1, p. 147-168, $2005<10.1590 /$ S0104-62762005000100006>.

BORBA, Julian. Participação política: uma revisão dos modelos de classificação. Revista Sociedade e Estado, v. 27, n. 2, p. 263-288, $2012<10.1590 / \mathrm{S} 0102-$ 69922012000200004>.

BORBA, Julian; RIBEIRO, Ednaldo A. Participação convencional e não convencional na América Latina. Revista Latino-Americana de Opinión Pública, v. 1, p. 53-76, 2010.

BOURDIEU, Pierre. O campo político. Revista Brasileira de Ciência Política, n. 5, p. 193-216, $2011<10.1590 /$ S0103-33522011000100008>.

BRADY, H. E. Political participation. In: J. P. Robinson (org.). Measures of political attitudes. San Diego, CA: Academic Press, 1999. p. 737-801.

CHAPMAN, Jennifer. Politics and reformation of gender. London: Routledge, 1993.

DAHLERUP, Drude. Women, politics, and quotas. New York: Routledge, 2006.

DULMER, Hermann; INGLEHART, Ronald; WELZEL. Christian. Testing the theory of modernization: measurement and explanatory aspects. World value survey, v. 8, n. 2, p. 68-100, $2015<$ www.worldvaluessurveys.org> (fev. 2016).

FRANCESCHET, Susan; KROOK, Mona; PISCOPO, Jennifer (orgs.). The impact of gender quotas. Oxford: Oxford University Press, 2012.

FOX, Richard L.; LAWLESS, Jennifer L. Entrando na arena? Gênero e a decisão de concorrer a um cargo eletivo. Revista Brasileira de Ciência Política, n. 8, p. 129-163, $2012<10.1590 /$ S0103-33522012000200006>.

GAXIE, Daniel. As lógicas do recrutamento político. Revista Brasileira de Ciência Politica, n. 8, p. 165-208, $2012<10.1590 /$ S0103-33522012000200007>.

GOHN, Maria da Glória. Conselhos gestores e participação sociopolitica. São Paulo: Cortez, 2003. 
HINTON, Nicole; MOSELEY, Mason; SMITH, Amy Erica. La igualdad en la participación política en las Américas. In: M. Seligson; A. E. Smith; E. Zechmeister (orgs.). La cultura política de las Américas, 2012: hacia la igualdad de oportunidades. Nashville: Vanderbilt University, Lapop, 2012.

LENA JÚNIOR, Hélio de. Uma reflexão acerca do conceito de cultura política. Confluências, v. 12, n. 1, p. 155-176, 2012.

KROOK, Mona Lena; MACKAY, Fiona (orgs.). Gender, politics, and institutions: toward a feminist institutionalism. New York: Palgrave, 2011.

KROOK, Mona L; NORRIS, Pippa. Beyond quotas: strategies to promote gender equality in elected office. Political Studies, v. 62, n. 1, p. 2-20, $2014<10.1111 / 1467$ 9248.12116>.

KUSCHNIR, Karina; CARNEIRO, Leandro Piquet. As dimensões subjetivas da política: cultura política e antropologia da política. Revista Estudos Históricos, v. 13, n. 24, p. 227-250, 1999.

MIGUEL, Luis Felipe; MARQUES, Danusa; MACHADO, Carlos. Capital familiar e carreiras políticas no Brasil: gênero, partido e região nas trajetórias para a Câmara dos deputados. Dados, v. 58, n. 3, p. 721-747, $2015<10.1590 / 00115258201557>$.

MOISÉS, José Álvaro. Os brasileiros e a democracia. São Paulo: Ática, 1995.

NICOLAU, Jairo. O sistema eleitoral de lista aberta no Brasil. Dados, v. 49, n. 4, p. $689-720,2006<10.1590 /$ S0011-52582006000400002>.

NORRIS, Pippa. Conclusion. In: Pippa Norris; Joni Lovenduski (orgs.). Gender and party politics. Londres: Sage, 1993.

NORRIS, Pippa. Political activism: new challenges, new opportunities. In: Carles Boix; Susan C. Stokes (orgs.). The Oxford handbook of comparative politics. Oxford: Oxford University Press, p. 628-652. 2007. <http://ksghome.harvard.edu/ pnorris/ Acrobat/Boix\&stokes-chap26.pdf> (1으 fev. 2016).

PIATTI-CROCKER, Adriana. Jumping on the bandwagon: explaining innovation and diffusion of gender quotas in Latin America. In: Adriana Piatti-Crocker (org.). Diffusion of gender quotas in Latin America and beyond: advances and setbacks in the last two decades. New York: Peter Lang, 2011.

PICHIER, Walter Arno. Tendências da sindicalização no Brasil: 1922-2000. Indicadores Econômicos FEE, v. 38, n. 3, p. 37-46, 2011.

POGREBINSCHI, Thamy; SANTOS, Fabiano. Participação como representação: o impacto das conferências nacionais de políticas públicas no Congresso Nacional. Dados, v. 54, n. 3, p. 259-305, $2011<10.1590 /$ S0011-52582011000300002>.

RELATORIO latinobarômetro. 2015 <www.latinobarometro.org> (20 jun. 2016).

SACCHET, Teresa. Capital social, gênero e representação política no Brasil. Opinião Pública, v. 15, n. 2, p. 306-332, 2009 <10.1590/S0104-62762009000200002>.

SANTO, Paula do Espírito. Portuguese civic culture: voter's attitudes and participation on politics. E-working paper, n. 3, Lisboa: Iscte, $2010<\mathrm{http}$ ://paperroom.ipsa.org/ papers/paper_105.pdf> (27 out. 2015). 
SANTOS, Fabiano; PAULA, Carolina de; SEABRA, Joana. Cotas e movimentos sociais nas estratégias partidárias de inserção das mulheres na vida parlamentar: os casos do Rio de Janeiro e Ceará nas eleições 2010 para a Câmara dos Deputados. In: J. E. D. Alves; C. Pinto e F. Jordão (orgs.). Mulheres nas eleições 2010. Rio de Janeiro: ABCP $\backslash S P M, 2012$.

SHIMIDT, Gregory. Gender quotas in Peru: origins, interactions with electoral rules, and re-election. In: Adriana Piatti-Crocker (org.). Diffusion of gender quotas in Latin America and beyond: advances and setbacks in the last two decades. New York: Peter Lang, 2011.

SCHWINDTER-BAYER, Leslie. Political power and womens representation in Latin America. New York: Oxford University Press, 2010.

URBINATI, Nadia. O que torna a representação democrática? Lua Nova, n. 67, p. 191-228, $2006<10.1590 /$ S0102-64452006000200007>.

VERBA, S.; SCHLOZMAN, K. L.; BRADY, H. E. Voice and equality: civic voluntarism in American politics. Cambridge, Mass.: Harvard University Press, 1995.

WVS. [Vários anos]. <www.worldvaluessurveys.org> (20 jun. 16).

\section{Sítios eletrônicos consultados}

INSTITUTO Patricia Galvão <agenciapatriciagalvao.org.br>.

INTER-Parliamentary Union (IPU) <www.ipu.org>.

AMERICASBAROMETER. American public opinion project (Lapop) <www. vanderbilt.edu/lapop/> vários acessos.

LATINOBARÔMETRO <www.latinobarometro.org $>$.

WORLD Values Survey (WVS) <www.worldvaluessurveys.org>.

DIEESE. Anuário das mulheres brasileiras. 2011. <www.spm.gov.br/sobre/ publicacoes/publicacoes/2011/anuario_das_mulheres_2011.pdf> (maio 2015).

IBGE. Síntese de indicadores sociais: uma análise das condições de vida da população brasileira. $2014<$ http://biblioteca.ibge.gov.br/> (maio 2015).

TSE. $<$ http://www.tse.gov.br>.

Autora correspondente:

Clara Maria Araújo

Rua das Laranjeiras, 585 ap. 904 - Laranjeiras

22240-005 Rio de Janeiro, RJ, Brasil

Recebido em: 18 fev. 2016

Aprovado em: 23 maio 2016 